\title{
Systematic Monitoring of Nitrate Contents in Imported Fresh Vegetables in UAE
}

\section{Zohuir A Balawna' ${ }^{1}$ Ideisan I Abu-Abdoun ${ }^{2 *}$, Nizar A Al-Haj Ali ${ }^{1}$, Abdulla S Janan ${ }^{1}$ and Nasra M Abd El-Mageed ${ }^{1}$}

${ }^{1}$ National Laboratories Department, Ministry of Climate Change and Environment, Sharjah, United Arab Emirates

${ }^{2}$ Department of Chemistry, University of Sharjah, Sharjah, United Arab Emirates

*Corresponding Author: Ideisan I Abu-Abdoun, E-mail: abuabdoun@sharjah.ac.ae.

Received: July 21, 2019; Published: July 26, 2019

DOI: $10.31080 /$ ASPS.2019.03.0358

\begin{abstract}
In this study, analysis of nitrate $\left(\mathrm{NO}_{3}^{-}\right)$content in fresh vegetables imported to United Arab Emirates (UAE) during the year 2017 was conducted, the main objective was determined whether estimated dietary exposure to nitrate poses a risk to human health and safety. During the time of this study samples of (240) different agricultural products (Potato, Lettuce, Beans, Pumpkin, Carrot, Cabbage, Cucumbers, Sweet pepper, Hot pepper, Onion, Tomatoes, Eggplant, Sweet potato, Radish, Parsley, Squash, Spinach, Cauliflower, Guava, Watermelon, Banana and Date were analyzed. The samples were obtained at the time of maturity directly and they were analyzed using ion chromatography. The average nitrate contents vary depending on the types of the examined product. the nitrate contents in vegetables depending on the type. The 240 different samples or parts of the selected agricultural 24 products (Potato, Lettuce, Beans, Pumpkin, Carrot, Cabbage, Cucumbers, Sweet pepper, Hot pepper, Onion, Tomatoes, Eggplant, Sweet potato, Radish, Parsley, Squash, Spinach, Cauliflower, Guava, Watermelon, Banana and Date) were analyzed. The average nitrate contents were the highest in Radish (2391.99 $\mathrm{mg} \mathrm{kg}^{-1}$ ), parsley (2336.4 $\mathrm{mg} \mathrm{kg}^{-1}$ ) and lettuce (2179.5 mg kg-1) and they were moderately high in spinach (967.41 mg kg-1) and cabbage (742.2 $\mathrm{mg} \mathrm{kg}^{-1}$ ). Low nitrate contents were found in bean $386.6 \mathrm{mg} \mathrm{kg}^{-1}$, onion $353.8 \mathrm{mg} \mathrm{kg}^{-1}$, gourd $325.2 \mathrm{mg} \mathrm{kg}^{-1}$ and hot pepper $299.4 \mathrm{mg} \mathrm{kg}^{-1}$. The results obtained shows that it is necessary to establish limits of nitrates contents of vegetables at the point of entry in every country.
\end{abstract}

Keywords: Monitoring of Nitrate Content; Fresh Fruits and Vegetables; Sampling Agricultural Products; Ion Chromatography; Acceptable Daily Intake (ADI)

\section{Introduction}

The content of nitrates in agricultural products is an important indicator of the quality of products and it has an important influence on the human health. Nitrate is itself non-toxic to humans and livestock however; its toxic metabolites, such as nitrite $\left(\mathrm{NO}_{2}^{-}\right)$ and later product such as N-nitroso compounds, are thought to be deleterious to health [1-4] (e.g. nitrites react with hemoglobin and produce methemoglobin, which enables to transport of oxygen at the cellular level). Nitrite may be formed in nitrate-containing food items like vegetables, if they are stored incorrectly. It has been established that nitrate levels found naturally in various fruits and vegetables are dependent upon several factors including; the use of fertilizers, geographical location and soil type, carbon dioxide concentrations (in greenhouse vegetables), seasonal light intensity and duration of light exposure and water availability [5-10]. The JECFA and the European Commission's Scientific Committee on Food, set the Acceptable Daily Intake (ADI) of nitrate at 0 - $3.7 \mathrm{mg}$ $\mathrm{kg}^{-1}$ of body weight. The U.S.A. Environmental Protection Agency set a reference dose of $\mathrm{NO}_{3}^{-}$at c. $7 \mathrm{mg} \mathrm{kg}^{-1}$ of body weight per day. The maximum recommended daily nitrate intake is $3.7 \mathrm{mg} \mathrm{kg}^{-1}$ body weight of nitrate ion equivalent to $220 \mathrm{mg}$ nitrate at $60 \mathrm{~kg}$ body weight was established by the former Scientific Committee on Food (SCF) and was reconfirmed by the Joint FAO/WHO Expert Committee on Food Additives (JECFA) in [11]. The fruit with 
the highest nitrate content is strawberries, followed by currents, gooseberries, raspberries and cherries. Apples were found to have only trace amounts of nitrates.

Nitrate concentrations in vegetables may also vary up to orders of magnitude dependent on the vegetable species and the part of the plant sampled. High concentrations of nitrate tend to accumulate in the leaves, roots, petioles or stems of certain plants meaning that leafy vegetables including lettuce or spinach, and root crops such as beetroot, may accumulate high concentrations of nitrate. In contrast, levels of nitrate in vegetables such as carrots or onions are likely to be lower $[5,12,13]$. The content of nitrates in vegetables divided regarding the content of nitrates (in $\mathrm{mg} \mathrm{kg}^{-1}$ of fresh sample) in five classes $[8,14,15]$.

\begin{tabular}{|l|l|}
\hline Class & Nitrate content $(\mathbf{m g} / \mathbf{K g}$ fresh weight \\
\hline Class I & Very low, $<200$ \\
\hline Class II & Low, 200 to $<500$ \\
\hline Class III & Middle, 500 to $<1000$ \\
\hline Class IV & High, 1000 to $<2500$ \\
\hline Class V & Very high, $>2500$ \\
\hline
\end{tabular}

Table 1: Classification of vegetables according to nitrate content.

On the other hand, fruit contains substantially less nitrates, in most cases below $10 \mathrm{mg} \mathrm{kg}^{-1}$ of fresh sample $[6,16]$.

This study evaluates the content of nitrates in imported agricultural products, as the quantity of nitrates, which can establish and contribute to the health safety of food products.

\section{Materials and Methods}

The program of sampling agricultural products

Selected 24 different agricultural products were included; approximately a total of approximately 240 samples of fruit, field crops and vegetables were collected randomly from different local ports of entry for monitoring purposes. Immediately after sampling, the samples were taken to the laboratory using cold-storage bags.

\section{Analytical equipment}

A Thermo Scientific ${ }^{\mathrm{TM}}$ Dionex $^{\mathrm{TM}}$ ICS-2100 Reagent-Free ${ }^{\mathrm{TM}}$ IC (RFIC) ${ }^{\mathrm{TM}}$ System (Thermo Fisher Scientific, Sunnyvale, CA, USA) was used in this study.

\section{Preparation of reagents and standard solutions}

All solutions were prepared in deionized (DI) water with a specific resistance of at least $18 \mathrm{M} \Omega$-cm (Millipore, Billerica, MA, USA). All reagents were ACS grade.

Working standards were 1, 5, 15 and $20 \mu \mathrm{gmL}^{-1}$ prepared from diluting standard reference material (Accustandard/aqueous solution) containing $100 \mathrm{\mu gmL}^{-1}$ nitrate standards in deionized water milliQ. These calibration standards were replaced daily.

\section{Preparation of the vegetable's samples}

Nitrate concentration was measured according to the method described by Chou., et al. [17]. Fresh vegetables samples were carried to the National Laboratories Department, Ministry of Climate Change and Environment, located at Sharjah city - Sharjah, UAE.

Prior to analysis, non-edible parts of each sample were removed, cleaned carefully rinsed with tap water and then with deionized water, drained on tissue paper, a total of $1.0 \mathrm{Kg}$ of each sample were thoroughly homogenized and prepared to analysis. Five grams of the homogenized sample were accurately weighed into a $100 \mathrm{ml}$ volumetric flask, $100 \mathrm{ml}$ deionized water milliQ added, the flask was placed in an ultrasonic bath with stirred for 5 min at $40^{\circ} \mathrm{C}$, then placed in a boiling water bath at $80^{\circ} \mathrm{C}$ for $1 \mathrm{hr}$. After cooling to room temperature, the volume adjusted to $100 \mathrm{~mL}$ with deionized water, filtered (using Whatman 15 filter paper), and the extract was further filtrated through $0.22 \mu \mathrm{m}$ syringe filter PTFE membrane. The first filtrate of $3 \mathrm{~mL}$ was discarded, and the following filtrate of 5 $\mathrm{mL}$ was collected for the determination of nitrate in samples. All samples were immediately analyzed within one hour of sample preparation.

\section{Accuracy}

The accuracy of the procedure was assessed by performing recovery experiments. Cucumber, cabbage, cauliflower, eggplant, pumpkins, sweet pepper, sweet potatoes, squash and tomatoes samples were spiked by adding $1.0 \mathrm{mg} \mathrm{kg}^{-1}$ nitrate.

The results obtained after the extraction procedure represented $100 \%$ recovery. The experimental recovery was obtained from difference between sample and spiked sample, according to the following equation: (Total analyte found - analyte originally present) $\times 100 /$ analyte spike $=$ percentage recovery $(\%)$. A Spiked sample were analyzed in triplicate, including a blank test to evaluate the 
mean recoveries $96.67953 \%$. The linear spiked calibration curves were obtained with correlation factor $\mathrm{R}^{2}=0.9996$, the average RSD were $3.083 \%$ and uncertainty $0.21 \%$

Data analysis

Thermo Scientific ${ }^{\mathrm{TM}}$ Dionex $^{\mathrm{TM}}$ Chromeleon $^{\mathrm{TM}}$ Chromatography Data System (CDS) software.

\section{Results and Discussion}

Nitrate content in agricultural products

The results of the investigation of the nitrate contents, of the selected agricultural products are reported in Table 2. It was shown that the highest mean nitrate concentrations in leafy vegetables than other agricultural products moreover, there were a large variation.

\begin{tabular}{|c|c|c|c|c|c|c|c|c|}
\hline \multirow[t]{3}{*}{ Sample } & \multirow{3}{*}{$\begin{array}{c}\text { Number of } \\
\text { samples }\end{array}$} & \multirow{3}{*}{ Mean } & \multirow{3}{*}{ Range } & \multicolumn{5}{|c|}{ Classes of nitrate concentration (mg Kg $\left.{ }^{-1}\right)(\%)$} \\
\hline & & & & $<200$ & $200-500$ & $500-1000$ & $1000-2500$ & $>2500$ \\
\hline & & & & I & II & III & IV & $\mathbf{V}$ \\
\hline Radish & 9 & 2391.996 & $0-5742.554$ & 1 & & & 4 & 4 \\
\hline Parsley & 10 & 2336.4 & $0-6184.4$ & 3 & & & 4 & 3 \\
\hline Lettuce & 10 & 2179.534 & $0-7327.4$ & 2 & 1 & 1 & 2 & 4 \\
\hline Spinach & 10 & 967.4132 & $0-4982.974$ & 5 & 1 & & 3 & 1 \\
\hline Cabbage & 10 & 742.2358 & $0-1947.744$ & 3 & 5 & & 2 & \\
\hline Mint & 10 & 21.6 & $0-21.6$ & 10 & & & & \\
\hline Gourd & 10 & 325.2712 & $0-913$ & 5 & 2 & 3 & & \\
\hline Hot pepper & 10 & 299.4988 & $0-788.554$ & 6 & 1 & 3 & & \\
\hline Cauliflower & 10 & 212.269 & $0-986$ & 7 & 2 & 1 & & \\
\hline Squash & 10 & 169.0182 & $0-676.798$ & 6 & 2 & 2 & & \\
\hline Pumpkin & 10 & 116.2708 & $0-299.2$ & 8 & 2 & & & \\
\hline Eggplant & 10 & 82.8192 & $0-477.086$ & 8 & 2 & & & \\
\hline Cucumber & 10 & 76.7548 & $0-177.8$ & 10 & & & & \\
\hline Sweet pepper & 10 & 66.8494 & $0-184.13$ & 10 & & & & \\
\hline Tomatoes & 10 & 31.4941 & $0-61.372$ & 10 & & & & \\
\hline Beans & 10 & 386.6474 & $0-1446.8$ & 5 & 3 & & & \\
\hline Onion & 10 & 353.8968 & $0-2138.16$ & 7 & 1 & 1 & 1 & \\
\hline Potato & 10 & 133.2952 & $0-366.2$ & 8 & 2 & & & \\
\hline Carrot & 10 & 29.3144 & $0-67.02$ & 10 & & & & \\
\hline Sweet potato & 10 & 19.212 & $0-72.6$ & 10 & & & & \\
\hline Water melon & 10 & 247.4148 & 0-1008.8 & 7 & 3 & & & \\
\hline Banana & 10 & 62.129 & $0-237.158$ & 9 & 1 & & 2 & \\
\hline Guava & 10 & 55.065 & $0-267.92$ & 8 & 2 & & & \\
\hline Date & 10 & 2.056 & $0-20.56$ & 10 & & & & \\
\hline
\end{tabular}

Values are the mean \pm SD $(n=10)$.

Table 2: Nitrate contents in agricultural products. 
The mean nitrate value in leafy green vegetables samples were highly in radish sample (2391.99 $\mathrm{mg} \mathrm{kg}^{-1}$ ), Parsley (2336.4 $\mathrm{mg} \mathrm{kg}$ ${ }^{1}$ ), Lettuce (2179.5 $\mathrm{mg} \mathrm{kg}^{-1}$ ). Spinach (967.41 $\mathrm{mg} \mathrm{kg}^{-1}$ ) and Cabbage (742.23 $\mathrm{mg} \mathrm{kg}^{-1}$ ) had median concentration of nitrate while, Mint had very low nitrate content (21.6 $\mathrm{mg} \mathrm{kg}^{-1}$ ).

In summary, there is a large variation in nitrate content in different leafy green vegetables samples from a low of $21.6 \mathrm{mg} / \mathrm{kg}$ (Mint) to a high of $2391.9 \mathrm{mg} / \mathrm{kg}$ (Radish).

Fruiting vegetables group, nitrate content ranged from 31.49 to $325.27 \mathrm{mg} \mathrm{kg}^{-1}$ all within the range low and very low. Results showed that Nitrate concentrations in tested legumes were generally low it was $386.6 \mathrm{mg} \mathrm{kg}^{-1}$ in green bean.

The concentration of nitrate for the roots and tuber vegetables are low at 353.89, 133.29 and $29.31 \mathrm{mg} \mathrm{kg}^{-1}$ in Onion, Potatoes and Carrots, respectively which considered major components in the diet of many countries.

On the other hand, our results showed that tested fruits samples (Banana, Guava and Date) were very low ranged from 2.05 to $62.1 \mathrm{mg} \mathrm{kg}^{-1}$ except Watermelon nitrate content which was found low as $247.41 \mathrm{mg} \mathrm{kg}^{-1}$

This variation in data may be due to different environmental conditions (i.e. length of exposure to sunlight, cultivation methods and seeding time).

Based upon the maximum levels which was specified by European Commission Regulation, data showed that the investigated vegetables and fruits were safe for consumption except some leafy vegetables the mean is more than three times higher than other vegetable groups.

Many studies showed the nitrate content in vegetables can vary from 1 to $10,000 \mathrm{mg} / \mathrm{kg}$, the level of nitrate variation depends not only on genetic factors such as kinds or strains of the vegetables, but also on environmental factors such as nitrogen content of the soil, temperature, amount of sunlight and conditions of cultivation and storage [17-19].

Monitoring nitrate in crops that are regularly imported and contain high levels of nitrate to create national database, hazard analysis and critical control points (HACCP). Another aspects of this study stress on the needs to train and educate farmers and advise them to observe good agriculture practice (GAP) to minimize nitrate concentrations in vegetables and fruits, and to import control body to import fruits and vegetables from reliable sources and maintain proper records to enable source tracing when required, as the need to develop a standard specification control special maximum allowable limits of nitrates in agricultural and food products.

\section{Conclusions}

Studies on monitoring of nitrate concentration contaminations in different foodstuffs is important and major health and safety requirements in every country.

The results reported in this study of the monitoring nitrate in fresh vegetables were close to results of investigations reported.

\section{Ackowledgement}

This work carried out at the National Laboratories Department, Ministry of Climate Change and Environment (MOCCAE), Sharjah. Support to this work from (MOCCAE) and the University of Sharjah (UOS) is gratefully acknowledged.

\section{Bibliography}

1. Mensinga TT., et al. "Health implications of exposure to environmental nitrogenous compounds". Toxicology Review 22 (2003): 41-51.

2. Pardo-Marín O., et al. "Monitoring programme on nitrates in vegetables and vegetable-based baby foods marketed in the Region of Valencia, Spain: levels and estimated daily intake". Food Additives and Contaminants: Part A: Chemistry, Analysis, Control Exposure and Risk Assessment 27 (2010): 478-486.

3. Ozdestan $\mathrm{O}$ and Uren A. "Development of a cost-effective method for nitrate and nitrite contents of some green leafy vegetables grown in the Aegean region of Turkey". Journal of Agricultural and Food Chemistry 58 (2010): 5235-5240.

4. Chung SW., et al. "Nitrate and nitrite levels in commonly consumed vegetables in Hong Kong". Food Additives and Contaminants 4 (2011): 34-41.

5. Maynard DN., et al. "Nitrate accumulation in vegetables". Advances in Agronomy 28 (1976): 71-118. 
6. Walters CL. "Nitrate and nitrite in foods, V". In: Hill M, editor Nitrates and nitrites in food and water". Chichester, UK: Ellis Horwood Limited series in Food Science and Technology (1991): 93-107.

7. Dejonckheere W., et al. "Nitrate in food commodities of vegetable origin and the total diet in Belgium (1992-1993)". Microbiologie - Aliments - Nutrition 12 (1993): 359-370.

8. Schuddeboom LJ. "Nitrates and nitrites in foodstuffs. Strasbourg: Council of Europe". (1993): 43.

9. Chung SY., et al. "Survey of nitrate and nitrite contents of vegetables grown in Korea". Journal of Food Additives and Contaminants 20.3 (2003): 621-628.

10. Matallana González MC., et al. "Nitrate and nitrite content in organically cultivated vegetables". Food Additives and Contaminants 3 (2010): 19-29.

11. JECFA. Evaluation of certain food additives. WHO Technical Report Series 913. WHO, Geneva, Switzerland (2002).

12. EFSA. "Nitrate in vegetables Scientific Opinion of the Panel on Contaminants in the Food chain1 (Question No EFSAQ-2006-071)". The EFSA Journal 689 (2008): 1-79.

13. Iammarino M., et al. "Monitoring of nitrites and nitrates levels in leafy vegetables (spinach and lettuce): a contribution to risk assessment". Journal of the Science of Food and Agriculture 94.4 (2014): 773-778.

14. Hord NG., et al. "Food sources of nitrates and nitrites: the physiologic context for potential health benefits". The American Journal of Clinical Nutrition 90.1 (2009): 1- 10.

15. Tamme T., et al. "Nitrate in leafy vegetables, culinary herbs, and cucumber grown under cover in Estonia: content and intake". Food Additives and Contaminants 3 (2010): 108-113.

16. Brkić D., et al. "Nitrate in Leafy Green Vegetables and Estimated Intake". African Journal of Traditional, Complementary and Alternative Medicines 14 (2007): 31-41.
17. Chou SS., et al. "A high-performance liquid chromatography method for determining nitrate and nitrite levels in vegetables". Journal of Food and Drug Analysis 11.3 (2003): 233-238.

18. European Commission: Scientific Committee for Food. Opinion on nitrate and nitrite. Annex 4 to Document III/5611/95. (1995): 1-25.

19. Quijano L., et al. "Risk assessment and monitoring programme of nitrates through vegetables in the Region of Valencia (Spain)". Food and Chemical Toxicology 100 (2017): 42-49.

\section{Volume 3 Issue 8 August 2019 \\ (C) All rights are reserved by Ideisan I Abu-Abdoun., et al.}

